\title{
Infection in AIDS
}

NFECTION WITH HUMAN IMMUNODEFICIENCY VIRUS type-1 (HIV-1) is associated with a wide spectrum of secondary infections. It is only through a concerted approach by microbiologists with expertise involving many different organisms that we can hope to control the secondary infections associated with HIV-1 infection and to prolong life until effective means for controlling the primary infection are available.

The Infection and Immunity Section of the Canadian Society of Microbiologists held a symposium on infections in acquired immune deficiency syndrome (AIDS) at the annual meeting of the society in Calgary in June 1990, with the objective of encouraging microbiologists unfamiliar with the problems associated with HIV-1 infection to consider expanded research in this important area.

The symposium was chaired by Dr John Gill, and covered a variety of topics related to primary HIV-1 infection and associated secondary infections. Dr Allan Ronald of the Departments of Medicine and Medical Microbiology, University of Manitoba opened the symposium with an overview of the epidemiology of HIV-1 infection, with a special emphasis on heterosexual transmission. Dr Mark Wainberg of the Lady Davis Institute for Medical Research, McGill University, Montreal then discussed selected aspects of the HIV-1 virus, specifically covering the isolation and characterization of variants resistant to currently available antiviral agents. Dr Clyde Crumpacker of Beth Israel Hospital, Harvard Medical School, Boston discussed the significant problems of herpes virus infections in AIDS. Cytomegalovirus
(CMV) is the leading cause of sight-threatening viral infection, and Epstein-Barr virus replication is associated with hairy leukoplakia. He discussec the possibility that CD4+ cells latently infected with HIV-1 could become coinfected with CMV or human herpes virus 6 , leading to activation o HIV-1 replication. Successful treatment of herpes virus infections will require new drugs anc strategies, as drug-resistant strains are increasin gy selected. Dr Ross Hill of the Department o Medicine, SunY Health Sciences Center, Brooklyr discussed the reciprocal importance of HIV-1 anc Mycobacterium tuberculosis infections (TB). The cumulative risk of TB is as high as 20 to $25 \%$ in AIDS patients, and nearly one-half of TB patient in certain 'geographic hot spots' are HIV seroposi tive. He then emphasized the need for additiona studies on the impact of atypical mycobacteria infections on the clinical course and survival o AIDS patients, and the current controversy on the merits of specific therapy for these infections Finally, Dr John Gill of the Department o Microbiology and Infectious Diseases, University of Calgary, discussed the most common as sociated infection - that due to Pneumocysti carinii. He emphasized the acute and prophylactic management of these infections, and stressed the need for the development of better diagnostic methods.

We hope that the following papers resulting from these proceedings will be of interest and stimulate readers from all backgrounds to con sider approaching the global problem of HIV-1 infection.

WL Albritton, MD, FRCPC, Professor and Head Department of Microbiology University of Saskatchewan Saskatoon, Saskatchewan.

MJ Gill, MB, ChB, FACP, FRCPC, Associate Professor Department of Microbiology and Infectious Diseases University of Calgary Calgary, Alberta

Proceedings of the Infection and Immunity Symposium held at the Annual Meeting of the Canadian Society of Microbiologists in Calgary. June 6, 1990, and sponsored by the Medical Research Council and National Health Research and Development Program, with industrial support from Burroughs Wellcome Inc, Lederle Laboratory Division and Rhône-Poulenc Pharma 


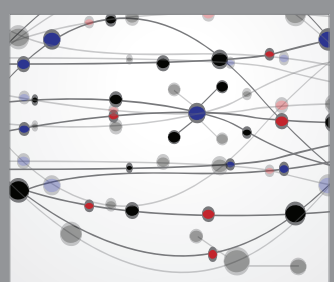

The Scientific World Journal
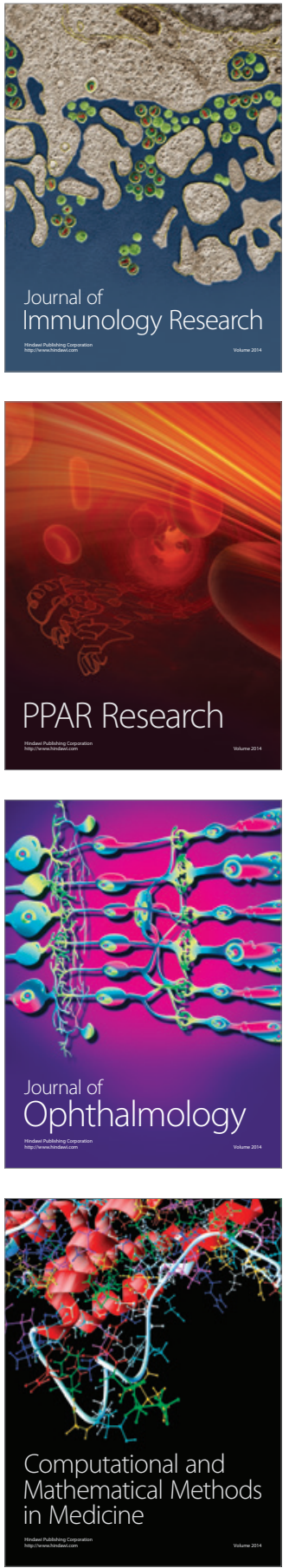

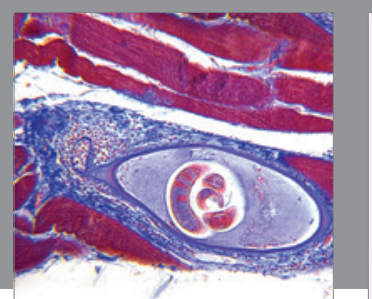

Gastroenterology Research and Practice

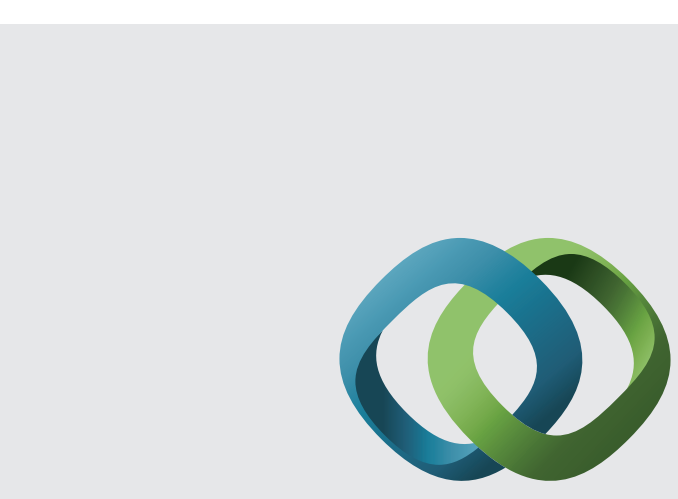

\section{Hindawi}

Submit your manuscripts at

http://www.hindawi.com
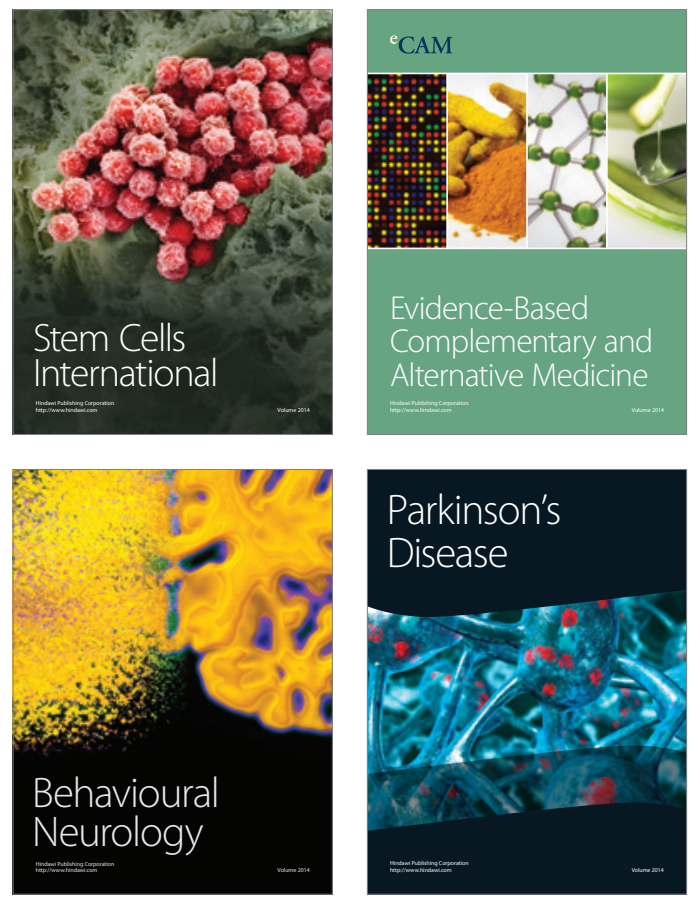
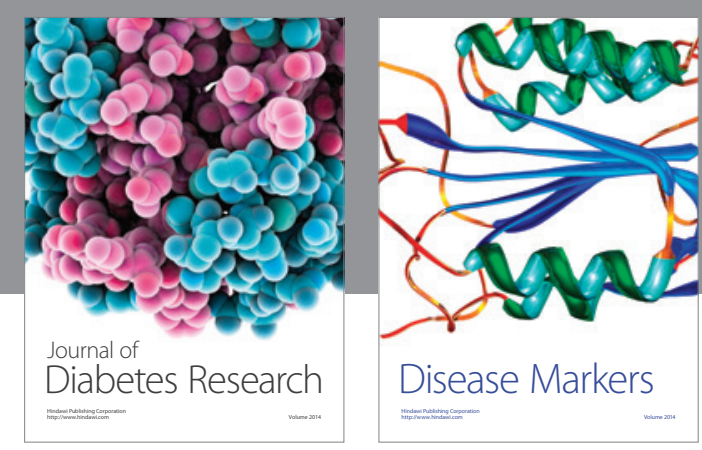

Disease Markers
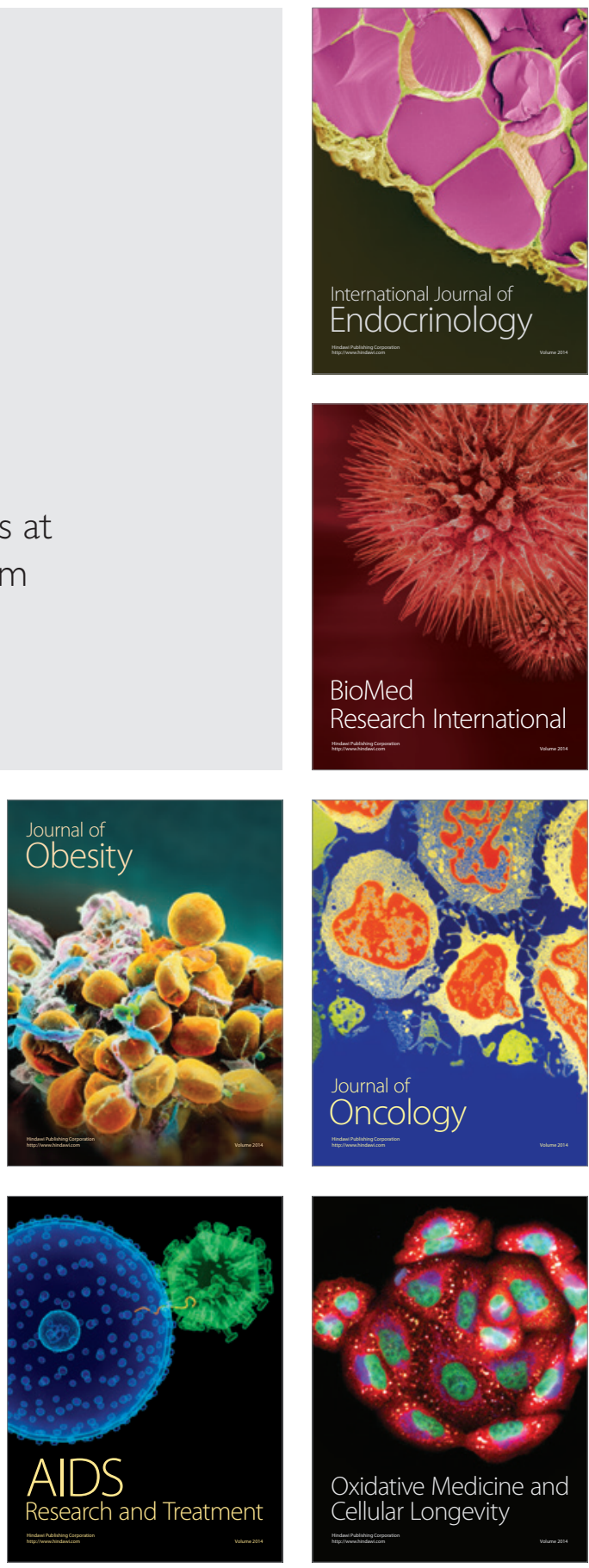